\title{
Aggregation Behavior of Polystyrene-Nanoparticles in Human Blood Serum and its Impact on the in vivo Distribution in Mice
}

\author{
Kristin Mohr ${ }^{1,3}$, Maria Sommer ${ }^{2}$, Grit Baier ${ }^{3}$, Susanne Schöttler ${ }^{3}$, Patricia Okwieka ${ }^{2,3}$, Stefan Tenzer ${ }^{4}$, Katharina Landfester ${ }^{3 *}$, Volker \\ Mailänder, ${ }^{2,3}$, Manfred Schmidt ${ }^{1}$ and Ralf Georg Meyer ${ }^{2}$ \\ ${ }^{1}$ Institute of Physical Chemistry, Johannes Gutenberg-University Mainz, Welder Weg 11,D-55021 Mainz, Germany \\ ${ }^{2}$ Department of Hematology, Oncology, and Pneumology, University Medical Center of the Johannes Gutenberg-University Mainz, Langenbeckstr, 1, D-55131 Mainz, \\ Germany \\ ${ }^{3}$ Max-Planck-Institute for Polymer Research, Ackermannweg 10, D-55128 Mainz, Germany \\ ${ }^{4}$ Institute for Immunology, University Medical Center of the Johannes-Gutenberg University Mainz, Langenbeckstrasse 1, D-55101 Mainz, Germany
}

\begin{abstract}
The interactions between nanoparticles (NPs) and proteins in complex biological application media such as blood serum are capable of inducing aggregate formation which can lead to subsequent changes in biological activity. Here, we correlate surface charge, aggregation-tendency, and surface serum protein adsorption with cellular uptake and biodistribution in mice.

Polystyrene-based NPs $(80-170 \mathrm{~nm})$ with different surface functionalizations were synthesized and incubated with human serum. Interaction of NPs with serum proteins and aggregate formation were analyzed by mass spectrometryanalysis and dynamic light-scattering. Influence of surface functionalization on specific cellular uptake and organdistribution was characterized.

Localization and organ targeting of intravenously applied NPs preferentially depended on their aggregationbehavior in the presence of serum. Whereas strongly aggregating particles mainly located to liver, non-aggregating particles distributed to all organs. Determination of aggregate formation of NPs in the presence of serum and further analysis of the protein corona allows for pre-selection of NPs for in vivo application.
\end{abstract}

Keywords: Pre-in-vivo screening; Protein nanoparticle interaction; Biodistribution; Human serum stability; Surface functionalization

\section{Introduction}

Nanoparticles (NPs) are promising delivery systems for in vivo application. They allow carrying incorporated substances to defined body areas. Thereby, NPs promise to facilitate targeted therapy without risking side-effects mediated by highly active or even toxic substances. Many efforts have been made to functionalize the surface of NPs and target their uptake by specific cells. Distribution and specific cellular targeting may allow clinical application e.g. in cancer medicine for the delivery of cytotoxic drugs, immune-modifiers or tumor-antigens [1]. When applied systemically by intravenous injection, many NPs are phagocytized by cells of the mononuclear phagocytic system (MPS) and subsequently remain in liver or spleen. Therefore, NP surfaces have been coated with "stealthing" molecules like poly(ethylene glycol) (PEG).

Very little is known about the impact of serum proteins and their interaction with the particle surface. Reports have been published analyzing the proteins bound to nanoparticles when applied to blood or serum [2-5]. It is likely that the protein corona which forms on the NP-surface in the presence of serum influences the NP's interaction with cellular surfaces. The protein corona therefore might interfere with cellular uptake and modify the interaction between particles themselves. Likely, specific proteins of the protein corona influence the tendency of NPs to form aggregates which in turn also influences their biodistribution in vivo [6-8].

Here, we show how functionality influences the aggregation behavior and cellular uptake. We used polymeric polystyrene NPs synthesized by the miniemulsion process [9]. This manufacturing process allows the synthesis of consistent and long-term stable preparation of particles of comparable size. Hereby, performing many analyses with a fixed batch of particles is advantageous. Aggregation studies were done by dynamic light scattering applying a previously developed pre-in vivo screening method [10]. This enabled us to analyze the effect of surface functionalization on aggregation and protein binding in the presence of human serum under physiologically relevant conditions. To allow analyzing the cellular uptake of NPs in cells of the peripheral blood as well as in professional antigen-presenting cells, the NPs were fluorescently labeled with boron-dipyrromethene (BODIPY) for flow cytometry and immune fluorescence. In addition, the particles were loaded with a near-infrared dye (IR-Dye 780) for in vivo imaging. Using quantitative high performance liquid chromatography coupled with mass spectrometry, we determined the composition of the protein corona. Using these particles, we were able to demonstrate that the pattern of protein binding in the presence of serum correlates with the tendency to form aggregates in vitro and in vivo. In addition, the charge of the particles' surface influenced their uptake in phagocytes and endocytosis as well as their biodistribution after intravenous application in mice.

\section{Experimental}

\section{Materials and methods}

Materials for NP synthesis: Styrene (Merck, Darmstadt, Germany)

*Corresponding author: Katharina Landfester, Max Planck Institute for Polymer Research, Ackermannweg 10, D-55128 Mainz, Germany, Tel: +49 6131 379-170; Fax: +49 6131 379-330; E-mail: landfester@mpip-mainz.mpg.de

Received March 24, 2014; Accepted April 14, 2014; Published April 24, 2014

Citation: Mohr K, Sommer M, Baier G, Schöttler S, Okwieka P, et al. (2014) Aggregation Behavior of Polystyrene-Nanoparticles in Human Blood Serum and its Impact on the in vivo Distribution in Mice. J Nanomed Nanotechnol 5: 193. doi:10.4172/2157-7439.1000193

Copyright: ( 2014 Mohr K, et al. This is an open-access article distributed unde the terms of the Creative Commons Attribution License, which permits unrestricted use, distribution, and reproduction in any medium, provided the original author and source are credited. 


\begin{tabular}{|c|c|c|c|c|}
\hline & PS-LUT & PS-LUT-COOH & PS-LUT-NH2 & PS-SDS \\
\hline Styrene, g & 6.0 & 5.88 & 5.88 & 6.0 \\
\hline Acrylic acid, g & & 0.12 & & \\
\hline AEMH, g & & 0.12 & \\
\hline Hexadecane, g & \multicolumn{3}{|c|}{0.25} \\
\hline Initiator V-59, g & \multicolumn{3}{|c|}{0.1} \\
\hline IR-780 iodide, g & 0.01 \\
\hline acrBODIPY, g & \multicolumn{3}{|c|}{0.005} \\
\hline Pt(II)-acac, g & 0.06 & 0.072 \\
\hline SDS, g & 0.6 & \\
\hline Lutensol AT50, g & \multicolumn{2}{|c|}{24.0} \\
\hline Water, g & & \\
\hline
\end{tabular}

Table 1: Recipe for the miniemulsion polymerization of polystyrene-based particles.

and acrylic acid (AA, Sigma-Aldrich, Seelze, Germany) were freshly distilled under reduced pressure and stored at $-20^{\circ} \mathrm{C}$ until use. Other reagents and solvents were commercial products and were used without further purification: 2-aminoethyl methacrylate hydrochloride (AEMH) (Aldrich, 90\%), the hydrophobic hexadecane (Aldrich, 99\%), the hydrophobic initiator 2,2'-azobis(2-methylbutyronitrile) (V-59) from Wako-Chemicals Japan, the surfactants Lutensol AT-50 (LUT) from BASF (Ludwigshafen, Germany), which is a poly(ethyleneoxide)hexadecyl ether with an EO block length of about 50 units, and sodium dodecyl sulfate (SDS) which was purchased from Aldrich. The IR-780 iodide dye $\left(\lambda_{\mathrm{ex}}=745 \mathrm{~nm}, \lambda_{\mathrm{em}}=820 \mathrm{~nm}\right)$ was purchased from Sigma Aldrich, acrBODIPY $\left(\left(\lambda_{\text {ex }}=500 \mathrm{~nm}, \lambda_{\text {em }}=540 \mathrm{~nm}\right)\right.$ was synthesized according to literature [11]; the oil-soluble $\mathrm{Pt}(\mathrm{II})$-acac-complex (platinum(II) acetylacetonate, 98\%) was purchased from STREM. Demineralized water was used throughout the experiments (Table 1).

Synthesis of nanoparticles: The synthesis of the functionalized and non-functionalized polystyrene-based NPs was performed using the direct miniemulsion co-polymerization method [12]. Briefly, for the synthesis of surface-functionalized polystyrene particles, a total monomer amount of $6.0 \mathrm{~g}$ (5.88 g styrene and $0.12 \mathrm{~g}$ functional comonomer) was used. For the synthesis of negatively charged carboxylic polystyrene particles styrene (PS-LUT-COOH), styrene, AA, $250 \mathrm{mg}$ hexadecane, $100 \mathrm{mg}$ V59 as initiator, $10 \mathrm{mg}$ IR-780 iodide, and $5 \mathrm{mg}$ acrBODIPY were mixed and added to the aqueous phase consisting of $24 \mathrm{~g}$ water and $600 \mathrm{mg}$ non-ionic surfactant Lutensol AT50. After $1 \mathrm{~h}$ of stirring, the mixture was homogenized by ultrasonication for $120 \mathrm{~s}$ at $90 \%$ intensity (Branson sonifier W450 Digital, $1 / 2$ " tip) at $0^{\circ} \mathrm{C}$ in order to prevent polymerization of the monomer(s). Polymerization was carried out at $72^{\circ} \mathrm{C}$ under gentle stirring for $12 \mathrm{~h}$. After the synthesis, polymeric NPs were cleaned 12 times by repetitive centrifugation/ redispersion (14000 rpm, 60 min, Sigma 3k-30) in demineralized water in order to remove the residual non-ionic surfactant Lutensol AT50 and - if any - water-soluble oligomers. For the formation of positively charged latex particles (PS-LUT-NH2), 2-aminoethyl methacrylate hydrochloride (AEMH) was added to the water phase. The preparation procedure, homogenization and polymerization steps were the same as described above. The non-functionalized NPs (PS-LUT and PSSDS) were prepared with $6 \mathrm{~g}$ of styrene without using a functional co-monomer. The non-functionalized polystyrene-based nanoparticle PS-LUT was stabilized with Lutensol AT50 and PS-SDS was stabilized using sodiumdodecyl-sulphate (SDS). All other ingredients and their used amounts, the preparation procedure, homogenization and polymerization steps were the same as described above. PS-LUT was cleaned by repetitive centrifugation/redispersion in demineralized water and PS-SDS was cleaned by dialysis over 3 days (MWCO: 12,000 g per mol). The amount of surfactant was lower than $0.1 \%$ compared to the polymer.

Zeta potential and particle charge detection (PCD) measurements: The zeta potential of NP was measured in $10^{-3} \mathrm{M}$ potassium chloride solution with a Nicomp zeta sizer (Nicomp Particle Sizing Systems, USA) at $20^{\circ} \mathrm{C}$. The amount of surface charged groups was calculated from the results of the titration experiments performed on a particle charge detector (Mütek $\mathrm{GmbH}$, Germany) in combination with a Titrino Automatic Titrator (Metrohm AG, Switzerland). The carboxylic groups were titrated against the positively charged polycation poly(diallyl dimethyl ammonium chloride) (poly-DADMAC). The amine groups on the particle surface were titrated against the negatively charged polyelectrolyte poly(ethylene sulfonate) (PES-Na). The titration was performed on $10 \mathrm{~mL}$ of the NP dispersion with a solid content of $1 \mathrm{~g} \cdot \mathrm{L}^{-1}$. The amount of groups per gram of polymer was calculated from the consumed volume of the polyelectrolyte solution. The amount of groups per gram of polymer was calculated from the consumed volume of the polyelectrolyte solution (equations see reference 12).

Scanning electron microscopy: Morphological studies were performed with scanning electron microscopy (SEM). The images were recorded by using a field emission microscope (LEO (Zeiss) 1530 Gemini, Oberkochen, Germany) operated with an accelerating voltage of $170 \mathrm{~V}$. Generally, the samples were prepared by diluting the capsule dispersion in cyclohexane or demineralized water (for redispersed samples) to about $0.01 \%$ solid content. A droplet of dispersion was placed onto silica wafers and dried under ambient conditions.

Light scattering experiments: All light scattering experiments were performed with an ALV-CGS 8F SLS/DLS 5022F goniometer equipped with eight simultaneously working ALV 7004 correlators, and eight QEAPD Avalanche photodiode detectors (ALV, Langen, Germany). A HeNe laser $(632.8 \mathrm{~nm}, 25 \mathrm{~mW}$ output power) was utilized as the light source. Correlation functions were analyzed by multi-exponential fits (for details see below), the initial slope of which yields the $\mathrm{z}$-average diffusion coefficient $\left(D_{z}\right)$ upon extrapolation to $q=0(q=4 \pi / \lambda \sin (\theta / 2)$ with $q$ the scattering vector, $\lambda$ the wavelength in the medium, and $\theta$ the scattering angle). By formal application of Stokes law $R_{\mathrm{b}}$ was derived as:

$$
R_{\mathrm{h}}=k T /\left(6 \pi \eta_{0} D_{\mathrm{z}}\right)
$$

For light scattering, serum solutions were filtered through Millex GS filters, $220 \mathrm{~nm}$ pore size (Millipore) into cylindrical quartz cuvettes (20 mm diameter, Hellma, Müllheim, Germany) which were cleaned by dust-free distilled acetone in a special acetone fountain. Concentration loss of serum proteins via filtration by Millex GS filters was found to be negligible.

The particles were prepared in Dulbecco's magnesium- and calcium-free phosphate buffered saline (PBS) buffer solution (GIBCO, Invitrogen), which was purified via filtration with Millex GS filter, $220 \mathrm{~nm}$ pore size (Millipore). The solutions were then placed into the dust-free light scattering cuvette without filtration in a dust-free laminar flow box, because the NPs could not be filtered most probably due to adsorption onto the filter. For measurements of NPs in serum, the particles were dissolved in filtered PBS buffer solution (GIBCO, Invitrogen) and added drop wise into the cuvette containing filtered serum. The cuvettes were incubated $20 \mathrm{~min}$ on a shaker at room temperature before measurement.

In order to compare light scattering data with in vivo experiments, a constant ratio between the number of PS particles and total protein $(\mathrm{NP} / \mathrm{SP})$ content is necessary. Due to the high turbidity of the particles at 


\begin{tabular}{|c|c|c|c|c|c|c|}
\hline \multirow[t]{2}{*}{ Particle } & \multirow[t]{2}{*}{$\begin{array}{c}\text { Number of } \\
\text { particles per } \mathrm{mL}\end{array}$} & \multicolumn{2}{|c|}{$\begin{array}{l}\text { Serum concentration in the } \\
\text { respective DLS experiment in } \mathrm{mg} / \mathrm{mL}\end{array}$} & \multirow[t]{2}{*}{$\begin{array}{l}\text { Number of particles per mg serum } \\
\text { protein (NP/SP) in vivo }\end{array}$} & \multicolumn{2}{|c|}{$\begin{array}{l}\text { Number of particles per mg serum protein } \\
\text { (NP/SP) DLS }\end{array}$} \\
\hline & & $c_{\mathrm{s}, \mathrm{iv}}$ & $c_{\mathrm{s}, \mathrm{conc}}$ & & $\mathrm{NP} / \mathrm{SP}_{\mathrm{iv}}$ & $\mathrm{NP} / \mathrm{SP}_{\text {conc }}$ \\
\hline PS-LUT & $1.02 \cdot 10^{14}$ & 6 & 60 & $8.5 \cdot 10^{10}$ & $8.5 \cdot 10^{10}$ & $8.5 \cdot 10^{9}$ \\
\hline PS-LUT-COOH & $2.5 \cdot 10^{15}$ & 6 & 60 & $2 \cdot 10^{12}$ & $2 \cdot 1012$ & $1.7 \cdot 10^{11}$ \\
\hline PS-LUT-NH2 & $1.02 \cdot 10^{14}$ & 6 & 60 & $8.5 \cdot 10^{10}$ & $8.510^{10}$ & $8.5 \cdot 10^{9}$ \\
\hline PS-SDS & $4.8 \cdot 10^{13}$ & 6 & 60 & $4 \cdot 10^{10}$ & $4 \cdot 10^{10}$ & $3.3 \cdot 10^{8}$ \\
\hline
\end{tabular}

Table 2: Comparison of particle and serum concentrations

the concentrations utilized for the in vivo experiments, light scattering measurements would be complicated by back and multiple scattering artifacts $[13,14]$. Therefore, the serum as well as the particle solution were diluted by a factor of 10 while keeping the nanoparticle/protein (NP/SP) ratio constant. This leads to the "in vivo" serum concentration of $c_{\mathrm{siv}}=6 \mathrm{mg} \cdot \mathrm{mL}^{-1}$ for the DLS analysis and to the in vivo NP/SP ratio (Table 2). Additionally, the particles were dissolved in undiluted serum $\left.\left(c_{\mathrm{s}, \text { conc }}=60 \mathrm{~g} \cdot \mathrm{L}^{-1}\right)\right)$ in order to investigate the effect of absolute serum concentration.

Primary blood cells and serum preparation: Human peripheral blood for cell and serum preparation was either obtained from healthy volunteers or by preparation from buffy-coat provided by the Department of Transfusion Medicine of the University Medical Center, Mainz, Germany. The use of these primary human materials was carried out after obtaining written informed consent and had been approved by the local ethics committee. For serum, peripheral blood was allowed to clot and was subsequently spun at $2500 \mathrm{~g}$ for $10 \mathrm{~min}$. In order to level out inter-individual variation of protein composition, serum of seven donors was pooled [10].

For the generation of dendritic cells (DC), peripheral blood mononuclear cells (PBMC) were isolated from healthy donor buffy coats by standard Ficoll separation as described [15]. Briefly, monocytes were isolated by plastic adherence. Therefore, $\mathrm{PBMC}$ were seeded into 6-well plates $\left(1.5 \times 10^{7} \mathrm{PBMC} /\right.$ well $)$ and allowed to adhere at $37^{\circ} \mathrm{C}$ for 1 $\mathrm{h}$ in $3 \mathrm{~mL}$ DC-medium (RMPI with $2 \%$ heat-inactivated pooled human serum (HS), $100 \mathrm{U} \cdot \mathrm{mL}^{-1}$ Penicillin, $100 \mathrm{U} \cdot \mathrm{mL}^{-1}$ streptomycin (Sigma Aldrich, Steinheim, Germany), L-glutamine (Lonza, Basel, Suisse). Non-adherent cells were removed by washing with PBS. Cells were incubated for 2 days at $37^{\circ} \mathrm{C}$ in DC-medium containing $800 \mathrm{U} \cdot \mathrm{mL}^{-1}$ granulocyte/macrophage-colony stimulating factor (GM-CSF, Bayer, Germany) and 500 to $1000 \mathrm{U} \cdot \mathrm{mL}^{-1}$ interleukin (IL)-4 (Miltenyi Biotec, Germany). It was replaced with DC-medium containing $1600 \mathrm{U} \cdot \mathrm{mL}^{-1}$ GM-CSF and $500 \mathrm{U} \cdot \mathrm{mL}^{-1} \mathrm{IL}-4$ at day 3 and 5. Immature DCs (iDCs) were harvested on day 6 by incubating cells for $10 \mathrm{~min}$ at $37^{\circ} \mathrm{C}$ with PBS/EDTA $(2 \mathrm{mM})$ and by repeated washing with cold PBS. iDCs were used freshly for the loading with NPs.

Adsorption of serum proteins onto the nanoparticles determined by LC-MS: The nanoparticle dispersion was diluted with ultrapure water to a constant particle surface concentration $(0.1$ $\mathrm{m}^{2}$ in $400 \mu \mathrm{L}$ ) and incubated with $900 \mu \mathrm{L}$ human serum for $1 \mathrm{~h}$ at $37^{\circ} \mathrm{C}$ under constant agitation. The particles were separated from the supernatant by centrifugation at $20000 \mathrm{~g}$ for $30 \mathrm{~min}$. The nanoparticles were washed with PBS and three centrifugation steps at $20000 \mathrm{~g}$ for $30 \mathrm{~min}$. Proteins were eluted from the particles using $7 \mathrm{M}$ Urea, $2 \mathrm{M}$ Thiourea and 4\% CHAPS and digested as described [16]. Mass spectrometry (MS) analysis of tryptic peptides was performed using a Waters Xevo G2 system, operated with typical resolving power of at least 20000. All analyses were performed using positive mode ESI using a NanoLockSpray source. LC-MS analysis was performed applying the method after Tenzer et al. [16] and data were processed through the
ISOQuant software pipeline for TOP3-based label-free quantification [17].

Particle incubation in whole blood: Blood collection was performed 1-2 $\mathrm{h}$ after breakfast from these volunteers by venipuncture on individual days, i.e. at a same time point during the day. Whole blood was drawn into as many S-Monovette ${ }^{\circledR}$ tubes as needed (Sarstedt, Germany) with lithium heparin (Li-heparin, 10-30 I.U. $\mathrm{mL}^{-1}$ in blood final concentration). The final volume in each S-Monovette ${ }^{\oplus}$ with heparin or EDTA tubes was $2.7 \mathrm{~mL}$, for the citrate tubes it was $3.0 \mathrm{~mL}$ which is the target value as given by the manufacturer. Immediately after venipuncture, the S-Monovette ${ }^{\circ}$ collection tubes were placed on a blood tube roller (SRT9, Stuart, UK) and were agitated for $10-15$ min. After this, the volume of each S-Monovette ${ }^{\star}$ was reduced to $1 \mathrm{~mL}$ and fluorescent NPs (labeled with $N$-(2,6-diisopropylphenyl)perylene3,4-dicarboximide (PMI)) were added into the S-Monovette ${ }^{\oplus}$ tubes at concentrations of $75,150,300$ and $600 \mu \mathrm{g} \cdot \mathrm{mL}^{-1}$ as indicated in the experiments. $300 \mu \mathrm{g} \cdot \mathrm{mL}^{-1}$ was used as a standard of concentration. The incubation periods varied between 2 to $8 \mathrm{~h}$. After the incubation period with the NPs whole blood was stained using different antibodies and red blood cells were lysed as given in the following section. More details on the procedure are described in [18].

Antibody staining and red blood cell lysis for flow cytometry of whole blood analysis: Quantification of NPs' cellular uptake in specific leucocytes was analyzed by flow cytometry. To label and prepare leucocytes for analysis, the following steps were performed: First, aliquots of $100 \mu \mathrm{L}$ of the blood samples were incubated with fluorochrome-conjugated monoclonal mouse anti-human antibodies (all from Becton Dickinson, Germany) for $25 \mathrm{~min}$ at room temperature. CD3+ T lymphocytes ( $\mathrm{T}$ cell) were stained with CD3 APC (Cat.-No. 345767), CD14+ monocytes with CD14 APC (Cat.-No. 555399), CD16+ neutrophil granulocytes with CD16 Alexa Fluor 647 (Cat.-No. 557710) and CD19+ B lymphocytes (B-cell) with CD19 APC (Cat.-No. 555415). Corresponding fluorochrome-conjugated monoclonal antibodies were used as isotype controls (APC-conjugated: Cat.-No. 555576 and Alexa Fluor-conjugated: Cat.-No. 557714 (Becton Dickinson, Germany)). All isotype controls showed no unspecific binding.

After antibody staining, red blood cells were lysed with $1.25 \mathrm{~mL}$ of BD FACS Lysing Solution (Cat.-No. 349202, Becton Dickinson, Germany) in $1.5 \mathrm{~mL}$ Eppendorf tubes (Eppendorf, Germany). The tubes were vortexed thoroughly before and after a lysing period of 10 $\mathrm{min}$. Then the samples were centrifuged (5 $\left.\mathrm{min}, 500 \mathrm{x} \mathrm{g}\left[\mathrm{m} \cdot \mathrm{s}^{-2}\right]\right)$ and washed twice with PBS (Invitrogen, Germany) before the cell pellet was finally re-suspended in $1000 \mu \mathrm{L}$ PBS for further analysis.

Flow cytometry measurements were performed on a CyFlow ML using FlowMax 2.57 software (Partec, Münster, Germany). The fluorescent dye PMI in the NPs was excited with a $488 \mathrm{~nm}$ laser and the fluorochrome-conjugated antibodies with a $640 \mathrm{~nm}$ laser. For analysis, cells were selected on a forward scatter/sideward scatter dot plot, thereby excluding cell debris. These gated events were then further analyzed for the FL1 and FL6 channels. The median fluorescence intensity (MFI) 
Citation: Mohr K, Sommer M, Baier G, Schöttler S, Okwieka P, et al. (2014) Aggregation Behavior of Polystyrene-Nanoparticles in Human Blood Serum and its Impact on the in vivo Distribution in Mice. J Nanomed Nanotechnol 5: 193. doi:10.4172/2157-7439.1000193

of the FL1 channel (filter $527 / 30 \mathrm{~nm}$ ) was used to analyze the cellular uptake of fluorescent NPs and FL6 (filter 675/20 nm) for antibody detection. The MFI was determined by $1 \mathrm{D}$ histograms. For all analyses of flow cytometry data FCS Express V3.0 (DeNovo Software, USA) was used.

The NPs preparations differed in the amount of the incorporated fluorescent dye. Therefore, UV-Vis absorption spectra of the dissolved latex particles confirmed the amount of incorporated PMI $(\mu \mathrm{g})$ per g polymer [12]. With these figures the median fluorescence intensity (MFI) was normalized and is given as normalized fluorescence intensity (nFL1).

Mouse strain: NOD.Cg-Prkdcscid IL2RgtmWjl/SzJ (NOD-SCID IL2R $\gamma$ null; NSG) mice were obtained from The Jackson Laboratory (Bar Harbor, ME) and bred under specific pathogen-free conditions in the Central Animal Facility at the University Medical Center Mainz [19]. All mouse strains were subject to regular health status controls and

\begin{tabular}{|c|c|c|c|c|c|}
\hline Particle & $\begin{array}{c}\boldsymbol{R}_{\mathbf{h}} \mathbf{\text { nm }} \\
\mathbf{( P B S )}\end{array}$ & $\boldsymbol{\mu}_{\mathbf{2}}$ & $\begin{array}{c}\text { Nanoparticles per } \\
\mathbf{m L} \text { dispersion }\end{array}$ & $\begin{array}{c}\text { Zeta potential } \\
\mathbf{m V} \mathbf{( p H ~ 7 . 4 )}\end{array}$ & $\begin{array}{c}\text { Groups } \\
\mathbf{p e r} \mathbf{n m}^{\mathbf{2}}\end{array}$ \\
\hline PS-LUT & 96 & 0.058 & $2.7 \cdot 10^{14}$ & -9 & - \\
\hline PS-LUT-COOH & 81 & 0.057 & $4.5 \cdot 10^{14}$ & -29 & 0.6 \\
\hline PS-LUT-NH2 & 89 & 0.049 & $3.4 \cdot 10^{14}$ & +4 & 0.1 \\
\hline PS-SDS & 170 & 0.14 & $4.8 \cdot 10^{13}$ & -37 & - \\
\hline
\end{tabular}

Table 3: Hydrodynamic radii measured in PBS, polydispersity expressed by the normalized second cumulant $\mu^{2}$, number of particles per $\mathrm{mL}$ dispersion, zeta potentials and the amount of functionalized groups of polystyrene-based particles.

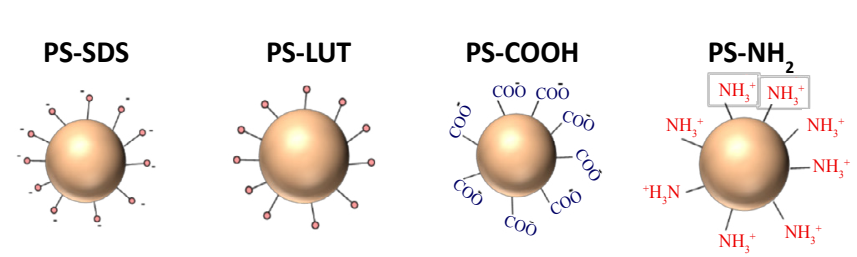

Figure 1: Schematic structure of investigated particles (from left to right): PSSDS, PS-LUT, PS-LUT-COOH, PS-LUT-NH ${ }_{2}$.

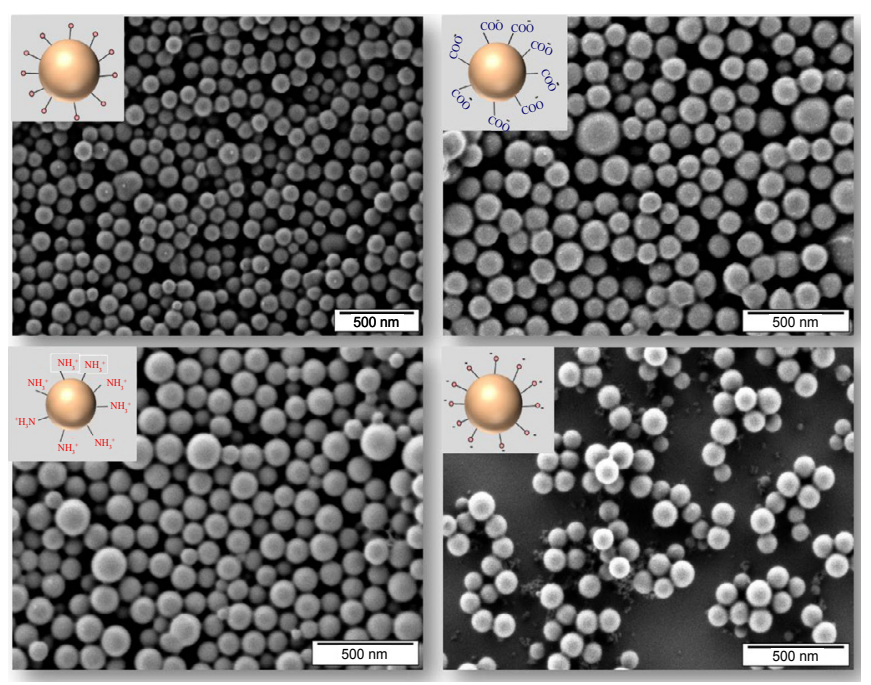

Figure 2: SEM images of investigated particles: PS-LUT (top left), negatively charged poly(styrene-co-acrylic acid) PS-LUT-COOH (top right) and PSSDS (below right), and positively charged poly(styrene-co-2-aminoethyl methacrylate) PS-LUT-NH2 (below left) were free of commonly tested viruses, parasites and bacteria. Male and female mice 1-4 month of age used for biofluorescence imaging (BFI) received water containing trimethoprim/sulfadoxine $\left(0.13 \mathrm{mg} \cdot \mathrm{mL}^{-1}\right.$; Virbac, Bad Oldesloe, Germany) weekly. The experiments outlined in this report were approved by local authorities and the institutional review board.

Biofluorescence imaging: For biofluorescence imaging (BFI), $100 \mu \mathrm{L}\left(37 \mu \mathrm{g} \cdot \mathrm{mL}^{-1}\right)$ of the respective NPs were applied intravenously to the tail vein of NSG mice. Animals were screened for fluorescence signals by measuring the infrared dye IR 780 iodide with the IVIS Spectrum (Xenogen, Alameda, CA, USA). For that purpose, mice were anesthetized with $2.5 \%$ Isofluran (Forene, Abvie, Ludwigshafen, Germany) and placed in the IVIS chamber for measurements. After 4 days, mice were sacrificed and the fluorescence signals in indicated organs and tissues were determined. For all measurements binning (CCD resolution) was set to 8 and F/Stop (Aperture) to 1 ; the subject height was set to $1.50 \mathrm{~cm}$. Data analysis was performed using Living Image ${ }^{\oplus}$ Software (Xenogen). For statistical analysis, the average radiant efficiency of the regions of interest was determined:

Total Radiant Efficiency $\left[\mathrm{p} \cdot \mathrm{s}^{-1}\right] /\left[\mu \mathrm{W} \cdot \mathrm{cm}^{-2}\right]$.

\section{Results}

Three differently functionalized polystyrene-based NPs stabilized with the non-ionic surfactant Lutensol AT50 and one with the anionic surfactant sodium dodecyl sulfate are synthesized (PS-LUT, PSLUT-COOH, PS-LUT-NH2, PS-SDS).The hydrodynamic radii of all investigated polystyrene particles obtained by dynamic light scattering, the zeta potential, and the functional groups per $\mathrm{nm}^{2}$ are listed in Table 3. The schematic structure of all particles is shown in Figure 1.

As a non-ionic surfactant was used for the synthesis of three NPs, the experimentally measured zeta potentials can be solely attributed to the functionalities located on the NP surface. The non-functionalized polystyrene NPs show a slightly negative zeta potential. This could be explained by a result of hydroxyl ion adsorption at the particle-water interface [20]. The zeta potential of the PS-SDS NPs is negative $(-37$ $\mathrm{mV}$ ) due to the presence of the anionic surfactant SDS (Figure 2).

All particles were characterized via dynamic light scattering (DLS) in buffer solution as well as in human blood serum. The correlation functions of the NPs, $g_{1, n p}(\mathrm{t})$, could be perfectly fitted by a sum of two exponentials:

$$
g_{1, n p}(\mathrm{t})=a_{1, n p} * \exp \left(-\frac{t}{\tau_{1, n p}}\right)+a_{2, n p} * \exp \left(-\frac{t}{\tau_{2, n p}}\right)
$$

with $a_{\mathrm{i}}$ and $\tau_{\mathrm{i}}=\left(q^{2} D_{\mathrm{i}}\right)^{-1}$ the amplitudes and decay times, respectively. The normalized second cumulant derived from the biexponential fit was very small for each of the samples and demonstrates the narrow size distribution of the NPs except for sample PS-SDS, which did not only exhibit a larger size but also a broader size distribution.

The fit of the serum correlation function was more complex and required a sum of three exponentials [10].

$$
g_{1, s}(\mathrm{t})=a_{1, s} * \exp \left(-\frac{t}{\tau_{1, s}}\right)+a_{2, s} * \exp \left(-\frac{t}{\tau_{2, s}}\right)+a_{3, s} * \exp \left(-\frac{t}{\tau_{3, s}}\right)
$$

A three exponential fit was necessary for the serum solution because it contains a cocktail of many proteins and lipids of various sizes, the precise composition of which is patient dependent [10]. If no aggregation occurs, the autocorrelation function (ACF) of the particles in serum solution could be perfectly fitted by a force fit of the sum of the individual correlation functions, 
Citation: Mohr K, Sommer M, Baier G, Schöttler S, Okwieka P, et al. (2014) Aggregation Behavior of Polystyrene-Nanoparticles in Human Blood Serum and its Impact on the in vivo Distribution in Mice. J Nanomed Nanotechnol 5: 193. doi:10.4172/2157-7439.1000193

$$
g_{1, m}(\mathrm{t})=f_{s} g_{1, s}(\mathrm{t})+f_{n p} g_{1, n p}(\mathrm{t})
$$

with the amplitudes $f_{\mathrm{s}}$ and $f_{\text {np }}$ the only variables. Please note that the known parameters $a_{\mathrm{i}}$ and $\tau_{\mathrm{i}}$ of the serum and polystyrene ACF were kept constant. In case of serum induced particle aggregation, Eq. 1 could not satisfactorily fit the correlation function of the particle/serum mixture. Therefore Eq. 1 had to be extended for the decay rate of the aggregates being formed according to:

$$
g_{1, m}(\mathrm{t})=f_{s} g_{1, s}(\mathrm{t})+f_{n p} g_{1, n p}(\mathrm{t})+f_{a g g} g_{1, a g g}(\mathrm{t})
$$

with $f_{\text {agg }}$ as the intensity contribution of the aggregates and

$$
g_{1, \mathrm{agg}}=a_{1, \mathrm{agg}} * \exp \left(-\frac{t}{\tau_{1, \mathrm{agg}}}\right)
$$

as the unknown correlation function of the aggregates. For polydisperse aggregates, a biexponential fit function for the aggregates may be used but was not necessary for the present samples. (a)

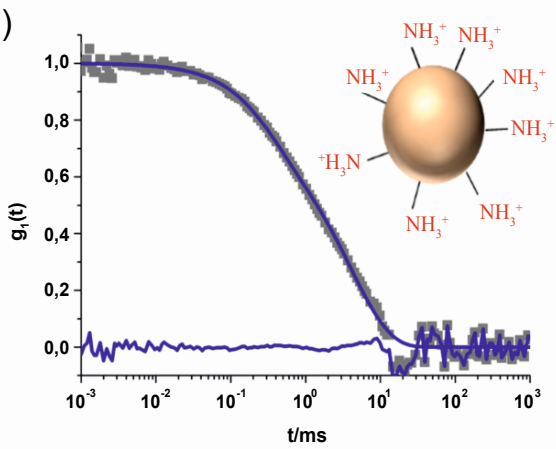

(c)

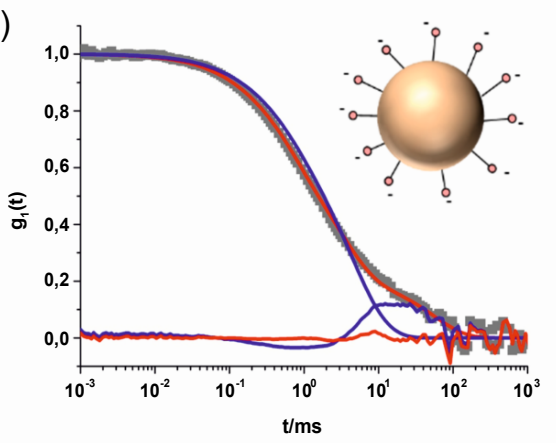

(e)

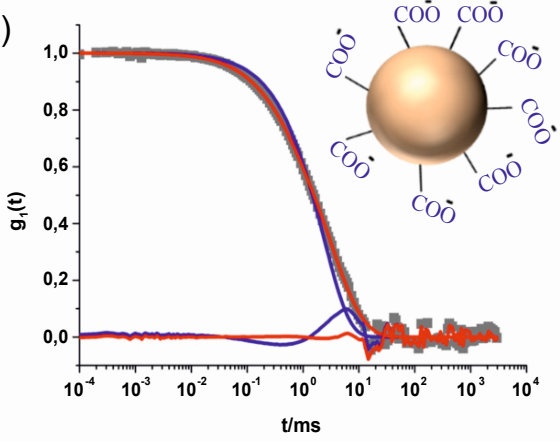

(b)

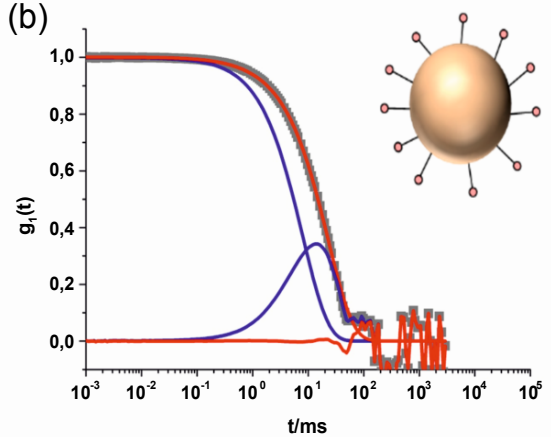

(d)

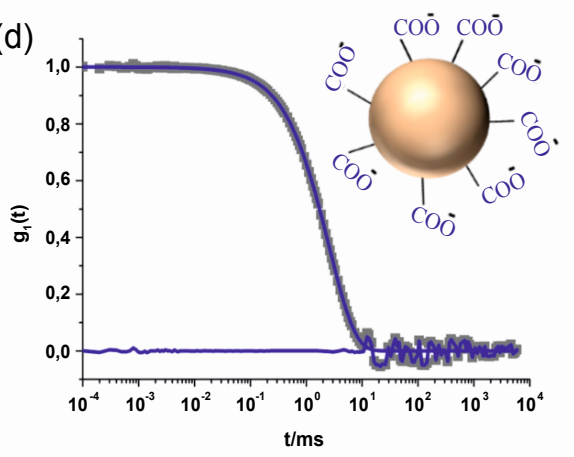

Figure 3: Dynamic light scattering in human serum: ACF and fits of (a) PS-LUT-NH2, (b) PS-LUT and (c) PS-SDS in serum (NP/SP ) (Table 4). Sample PS-LUT-COOH

\begin{tabular}{|c|c|c|c|c|}
\hline Particle & $\begin{array}{c}\text { Number particles per } \mathrm{mg} \text { serum } \\
\text { protein equals the ratio in the in } \\
\left.\text { vivo experiment (NP/SP }{ }_{\text {iv }}\right)\end{array}$ & Aggregate size (Rh) & $\begin{array}{l}\text { Number particles per mg serum } \\
\text { protein in undiluted human serum } \\
\left(\mathrm{NP}_{\mathrm{SP}} \mathrm{conc}_{\text {con }}\right)\end{array}$ & Aggregate size (Rh) \\
\hline PS-LUT & $8.5 \cdot 10^{10}$ & $200 \mathrm{~nm}$ & $8.5 \cdot 10^{9}$ & $200 \mathrm{~nm}$ \\
\hline PS-LUT-COOH & $2 \cdot 10^{12}$ & No aggregates & $1.7 \cdot 10^{11}$ & $250 \mathrm{~nm}$ \\
\hline PS-LUT-NH ${ }_{2}$ & $8.5 \cdot 10^{10}$ & No aggregates & $8.5 \cdot 10^{9}$ & No aggregates \\
\hline PS-SDS & $4 \cdot 10^{10}$ & $2 \mu \mathrm{m}$ & $3.3 \cdot 10^{8}$ & Macroscopic precipitation \\
\hline
\end{tabular}
did not show aggregation in diluted serum $\left(c_{\mathrm{s}, \mathrm{iv}}=6 \mathrm{mg} \cdot \mathrm{mL}^{-1}\right)(\mathrm{d})$ but aggregates occurred in undiluted serum $\left(c_{\mathrm{s}, \mathrm{conc}}=60 \mathrm{mg} \cdot \mathrm{mL}^{-1}\right.$ and $\mathrm{NP} / \mathrm{SP}$ conc $)(\mathrm{e})$. Red lines, fit by eq. 1 and the resulting residues; blue lines, fits with eq. 2 and the resulting residues, $\square$ data points of the ACF. Scattering angle $60^{\circ}$.

Table 4: Aggregation behavior of all investigated particles in the respective serum concentrations. Except for particle PS-LUT-COOH that shows only aggregation in the undiluted serum solution, the aggregation of the investigated particles does not depend on serum concentration. 
Citation: Mohr K, Sommer M, Baier G, Schöttler S, Okwieka P, et al. (2014) Aggregation Behavior of Polystyrene-Nanoparticles in Human Blood Serum and its Impact on the in vivo Distribution in Mice. J Nanomed Nanotechnol 5: 193. doi:10.4172/2157-7439.1000193

Page 6 of 10

An example of negligible serum interactions for particle PS-LUT$\mathrm{NH} 2$ is shown in Figure 3a, whereas PS-LUT (b) and PS-SDS (c) clearly show significant aggregate formation. The fits shown in Figure 3 yield aggregate sizes of $R_{\mathrm{h}, \mathrm{Agg}}=2 \mu \mathrm{m}$ for PS-SDS and $R_{\mathrm{h}, \mathrm{agg}}=200 \mathrm{~nm}$ for PSLUT.
A special situation is encountered for sample PS-LUT-COOH, which shows no aggregates in diluted serum $\left(c_{\mathrm{s}, \mathrm{iv}}=6 \mathrm{mg} \cdot \mathrm{mL}^{-1}\right)$ (Figure $3 \mathrm{~d})$, but detectable aggregates in undiluted serum $\left(c_{\mathrm{s}, \mathrm{conc}}=60 \mathrm{mg} \cdot \mathrm{mL}^{-1}\right)$ (Figure 2e) (Table 4).

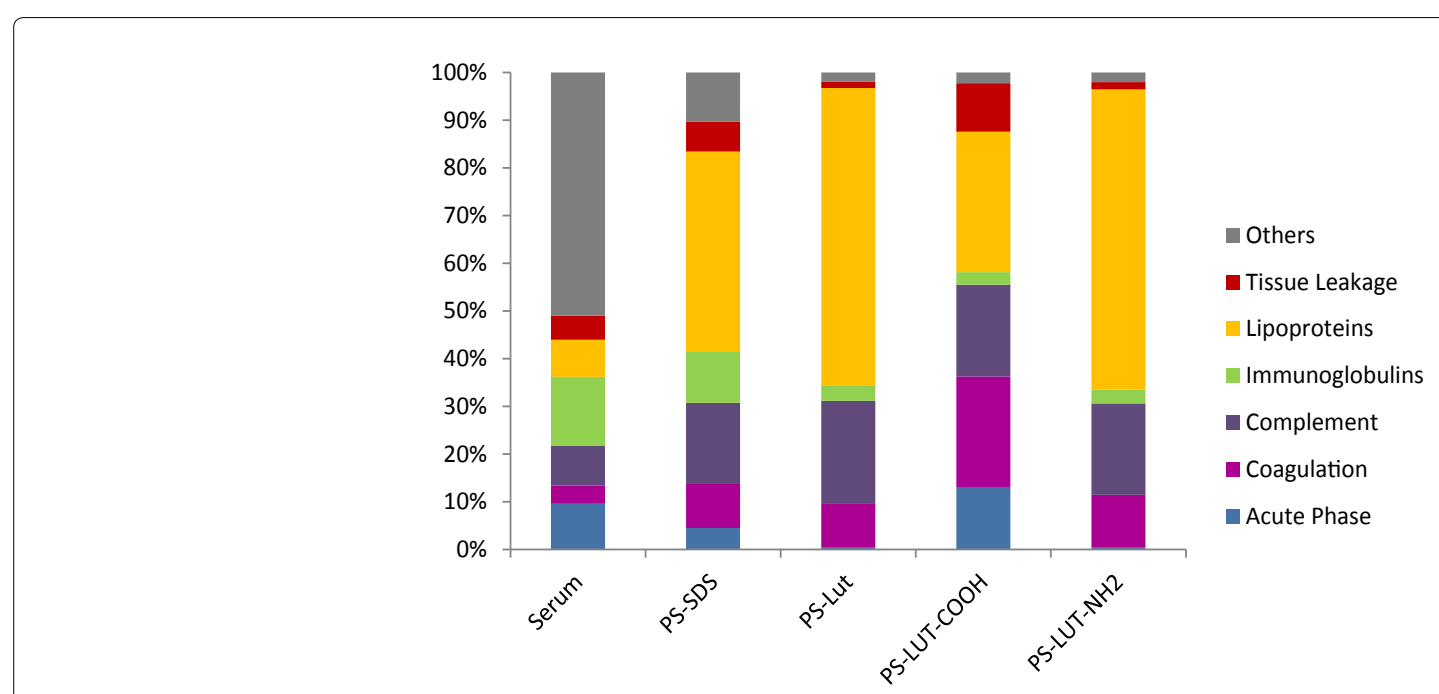

Figure 4: Adsorption of serum proteins on different NPs: Relative percentages of the proteins grouped according to their biological function compared to crude serum.
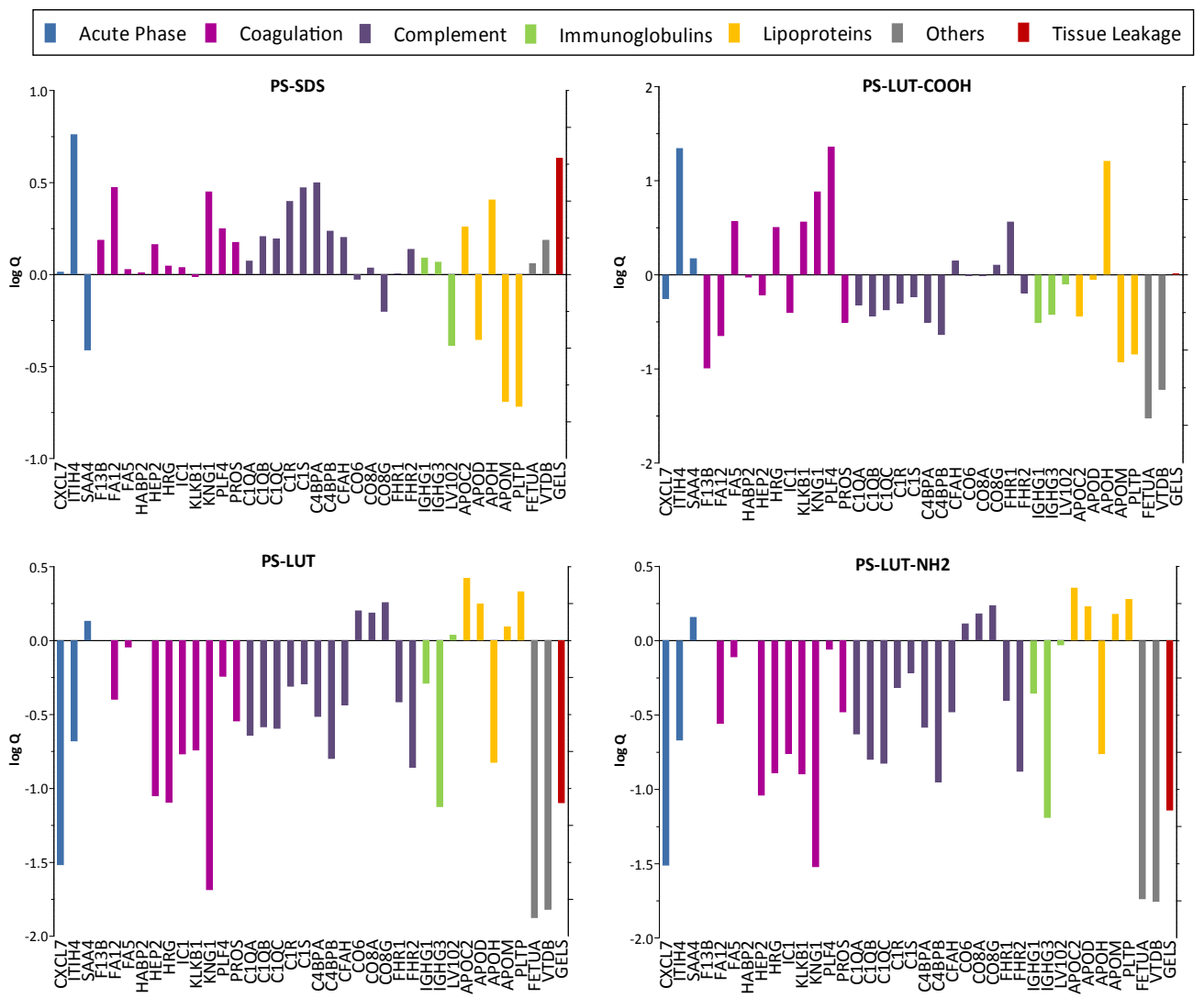

Figure 5: Adsorption of serum proteins on different NPs: Specific enrichment $(\log Q>1)$ or depletion $(\log Q<1)$ of proteins expressed as logarithm of ratio $Q(Q=$ mass fraction protein $x$ on particle/ mass fraction protein $x$ in serum). Only proteins which differ between the four NPs regarding their enrichment and depletion are plotted. (Abbreviations for the specific proteins are found in the SI.) 
Citation: Mohr K, Sommer M, Baier G, Schöttler S, Okwieka P, et al. (2014) Aggregation Behavior of Polystyrene-Nanoparticles in Human Blood Serum and its Impact on the in vivo Distribution in Mice. J Nanomed Nanotechnol 5: 193. doi:10.4172/2157-7439.1000193

\section{Protein adsorption}

In order to trace the origin of the aggregation behavior of the NPs in serum, the adsorption of serum proteins onto the NPs surface was analyzed by LC-MS for two biological replicates analyzed in two technical replicates each using a TOP3-based label-free quantification workflow [17]. The results are shown in Figure 4, detailed TOP3based quantification results for all detected proteins are provided in a supplementary Table. Reproducibility of label-free quantification was excellent $\left(R^{2}>0.98\right)$ between both biological and technical replicates (Supplementary Figure S1). Supplementary Figure S2 shows an example annotated fragmentation spectrum of the peptide EQLGPVTQEFWDNLEK derived from human Apolipoprotein A1. For clarity, data were aggregated and the proteins are displayed in seven different groups: acute phase proteins, coagulation proteins, complement proteins, immunoglobulins, lipoproteins, tissue leakage proteins, and "others". Human serum albumin is the most prominent protein among the latter group. The obtained binding profiles do not relate to the relative serum-concentration of the proteins (Figure 4). The concentration of lipoproteins and complement proteins is highly enriched on all four particles compared to serum, whereas the concentration of immunoglobulins and "other" proteins is significantly reduced. Interestingly, significantly more immunoglobulins adsorbed to PS-SDS compared to the other three NPs.

The protein corona profile is very similar for PS-LUT and PSLUT-NH2 showing the highest lipoprotein content, while acute phase proteins are almost not present in these protein coronas. On PS-LUT$\mathrm{COOH}$, the coagulation proteins are highly enriched, and also the tissue leakage and acute phase proteins are significantly increased.

For a better understanding of the specific differences in the protein composition on the four NPs, the proteins which differ between the NPs regarding their enrichment and depletion compared to serum are plotted in Figure 5. Once again, the similarity of protein adsorption to PS-LUT and PS-LUT-NH2 is immediately apparent. For PS-SDS, an enrichment of several individual proteins belonging to the group of coagulation and complement factors is shown, while these proteins are depleted on the three other NPs. As incubation of PS-SDS in serum results in a very strong aggregation, proteins of these groups are potential candidates to participate in the cross-linking of PS-SDS.

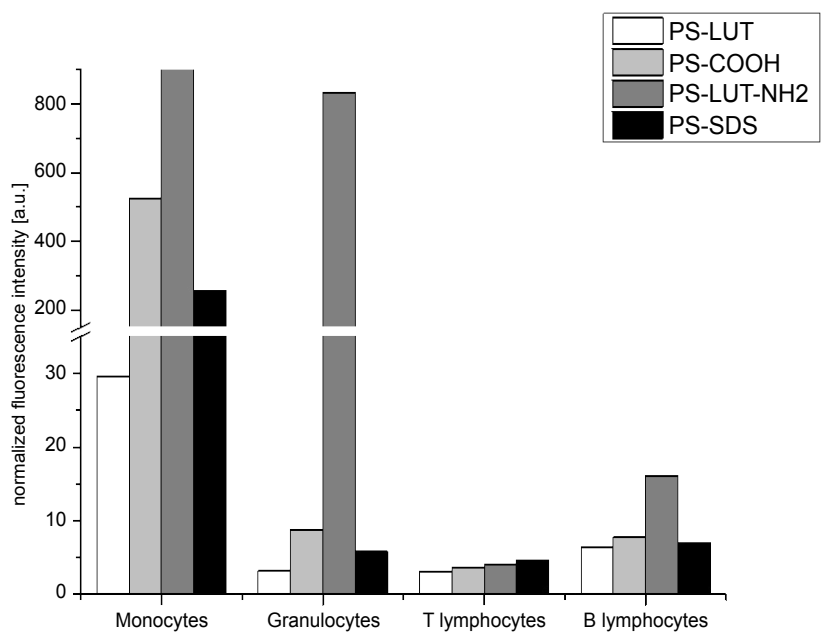

Figure 6: Uptake in peripheral blood leucocytes: Differential uptake of functionalized NP into different cell types after incubation in whole blood for $6 \mathrm{~h}$.

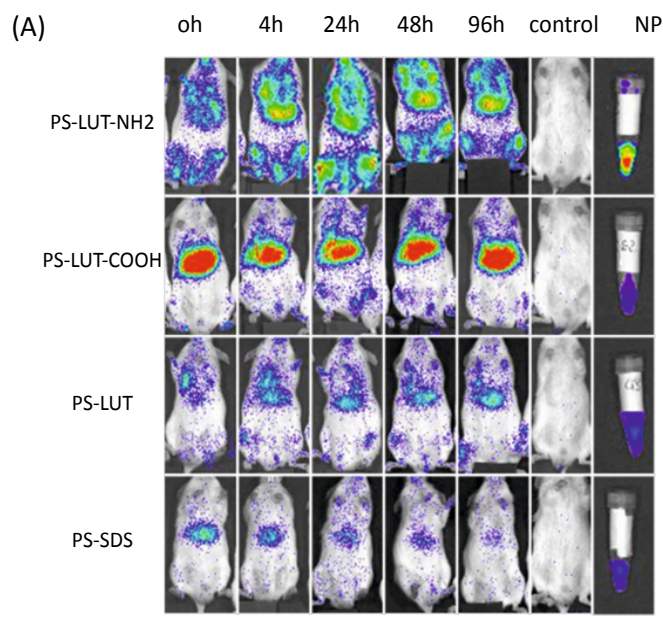

(B)
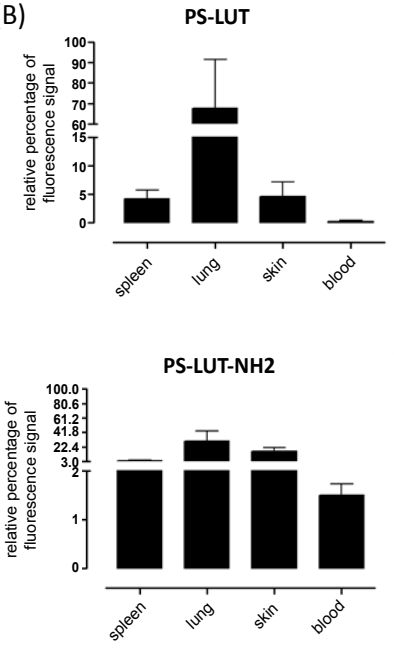

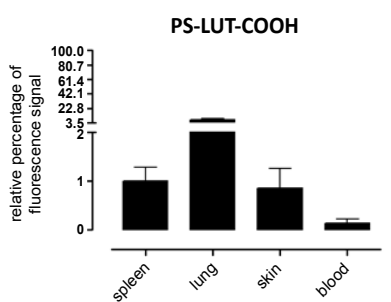

PS-SDS

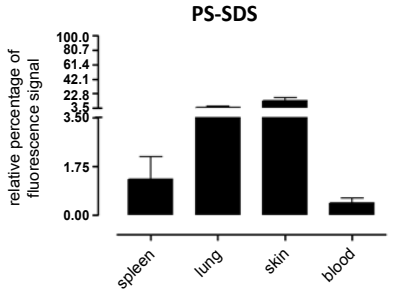

Figure 7: Biodistribution of NPs in NSG mice: (a) $37 \mu \mathrm{g} \cdot \mathrm{mL}^{-1}$ were applied intravenously with measurement of fluorescence signals (relative values in relation to liver-fluorescence) at different time points. On the very right side of relation to liver-fluorescence) at different time points. On the very right side of
every figure is the control displayed, that received no particles. (b) Quantitative analysis of fluorescence signals in diverse organs and tissues, $96 \mathrm{~h}$ after NPs application. The organ-specific fluorescence was calculated as percentage of liver-fluorescence (liver is set as $100 \%$, mean with SEM). PS-LUT $n=4$, PSLUT-COOH n= 4, PS-LUT-NH2 $n=5$, PS-SDS $n=3$.

Furthermore, the total amount of proteins adsorbed to PS-SDS is almost 4 times higher $\left(4,1 \mathrm{mg} \cdot \mathrm{m}^{-2} \mathrm{NP}\right)$ than for the other three NPs $\left(1,0-1,2 \mathrm{mg} \cdot \mathrm{m}^{-2} \mathrm{NP}\right)$ (results not shown).

\section{Uptake in peripheral blood leucocytes}

Next we investigated the uptake of NPs in whole blood leucocytes (Figure 6). Incubation in whole blood resulted in negligible uptake of all particles into T and B lymphocytes, whereas except for PS-LUT all particles showed a high uptake into monocytes. Only for the aminofunctionalized PS-LUT-NH2, a specific uptake in granulocytes was detected. Interestingly, only PS-Lut showed a markedly decreased uptake into monocytes confirming the "stealth" properties of Lutensol AT50 as a polyethylene glycol based surfactant. In granulocytes only the positively charged, non-aggregating PS-Lut-NH2 particles are taken up at a high extent. This could be due to the surface charge or it could be hypothesized that the size cutoff for NPs uptake is lower for neutrophils compared to monocytes. 


\section{Biodistribution of nanoparticles in NSG mice}

NPs were injected in the tail vein of NSG-mice to study their biodistribution in vivo (Figure $7 \mathrm{a}$ ). All particles are partly allocated to the liver region early after injection. In addition, the particles PSLUT and PS-LUT-NH2 were also detected in the lung early. Over time, all particles also distributed to other body areas. However, the signals for PS-SDS and PS-LUT-COOH mainly remained in the liver region. Since in vivo imaging only allows estimating the organ-distribution of the NPs, mice were sacrificed after $96 \mathrm{~h}$ and the isolated organs were also investigated for their fluorescence intensity. As the signal strength differed between different particles and intravenous injection is subject to slight variation between different animals, we normalized the fluorescence intensity of each isolated organ to that of the liver of the respective animal.

Figure $7 \mathrm{~b}$ outlines the relative fluorescence-intensity of peripheral blood, lung, spleen, and skin. The brain was also analyzed but did not show any signal in all animals (not shown). All other organs showed a fluorescence signal and results from the previous kinetic studies could be confirmed. Next to the liver, all particles also gave a moderate signal over the spleen. Nevertheless, PS-LUT-COOH and PS-SDS mainly remained in the liver, with PS-SDS showing a small but reproducible enrichment also in the skin. For PS-LUT-NH2 and PS-LUT, the strong in vivo signal over the lungs correlated with a strong organ-fluorescence after $96 \mathrm{~h}$. In addition, these particles also allocated to the back skin of the mice. The results were confirmed in four to eight further experiments. Since the shown percentages represent means of different single experiments, the high SEM error bars of lung (PS-LUT), skin (PS-LUT-COOH) and spleen (PS-SDS) can be explained by variations of intravenous particle injection between the individual experiments.

\section{Discussion}

The in vivo use of nanocarriers already is a clinical reality for applications like imaging and drug delivery [21,22]. In addition, delivery of potential antigens to professional antigen-presenting cells for vaccination is subject to current clinical trials [23]. As more nanocarriers are developed for clinical application, it is readily evident that we have a very limited understanding of how NP interaction with physiological fluids and structures impacts the spatial distribution and cellular uptake in vivo. In particular, the interaction of NPs with serum proteins has to be taken into account. Recently, an albumin coated NP for the delivery of paclitaxel has been approved for cancer treatment, indicating that binding to serum proteins might as well improve as well as compromise the therapeutic effect of NPs [24].

Here, we document the impact of surface functionalization of polystyrene NPs on serum protein-binding that in turn influenced aggregate formation. Three differently functionalized polystyrenebased NPs stabilized with the non-ionic surfactant Lutensol AT50 and one with the anionic surfactant sodium dodecyl sulfate are synthesized (PS-LUT, PS-LUT-COOH, PS-LUT-NH ${ }_{2}$, PS-SDS). The particles in aqueous solution show similar sizes $\left(R_{\mathrm{h}, \mathrm{PS}-\mathrm{LUT}}=96 \mathrm{~nm}, R_{\mathrm{h}, \mathrm{PS} \text {-LUT-COOH }}\right.$ $\left.=81 \mathrm{~nm}, R_{\mathrm{h} \text { PS-LUT-NH2 }}=89 \mathrm{~nm}\right)$ with very small polydispersities $\left(\mu_{2}=\right.$ $0.049-0.058)$ except the particle PS-SDS which shows a larger size $\left(R_{\mathrm{h}, \mathrm{PS}-\mathrm{SDS}}=170 \mathrm{~nm}\right)$ as well as a broader size distribution $\left(\mu_{2, \text { PS-SDS }}=\right.$ $0.14)$. Particles of this size are usually taken up by clathrin-mediated endocytosis (CME), an actin independent way of cellular uptake carried out by virtually all cells [25]. However, when incubated with human mononuclear cells from the peripheral blood, the tested particles were only taken up by monocytes and granulocytes, not lymphocytes. When we loaded our NPs to myeloid dendritic cells, we found strong uptake into the cytoplasm of these cells, which is in line with the previous findings. The selective uptake of all 4 particles by professional antigenpresenting cells suggests that they were taken up by phagocytosis rather than non-specific cellular uptake.

The DLS analysis of the non-functionalized and formally (in water) slightly negatively charged particle PS-LUT (zeta potential: $-9 \mathrm{mV}$ ) clearly shows the formation of aggregates with a hydrodynamic radius of Rh,agg,PS-LUT $=200 \mathrm{~nm}$ in undiluted $\left(\mathrm{c}_{\mathrm{Sconc}}=60 \mathrm{mg} \cdot \mathrm{mL}^{-1}\right)$ as well as in diluted human blood serum $\left(\mathrm{c}_{\mathrm{S}, \mathrm{iv}}=6 \mathrm{mg} \cdot \mathrm{mL}^{-1}\right)$. LC-MS analysis of the protein corona reveals a strong enrichment of lipoproteins while acute phase proteins as well as immunoglobulins are depleted. The high percentage of lipoproteins is particularly prominent for the particles PS-LUT and PS-LUT-NH2. The corona forming protein mixture might cause the slight aggregation of the particles PS-LUT and PS-LUT$\mathrm{NH} 2$ in human blood. Biodistribution of nanocarriers depends on size, charge, and reactive groups on the surface [26]. Most particular structures accumulate in the liver and to a lesser extend in lungs and spleen. However, size and surface have an impact on organ-deposition in other target organs like brain and skin. As contact with serum lead to aggregate formation and protein-corona, we hypothesized that these effects rather than the original functionalization affect in vivo distribution. PS-LUT and PS-LUT-NH $\mathrm{N}_{2}$ differed from the other particles as the main fraction of corona-building proteins after serum incubation were lipoproteins and even the relative distribution of proteins within the groups were similar between the groups. Interestingly, these were the two particles with the strongest enrichment in lung as well as in the skin. The uptake in skin and lungs displayed a specific distribution and was not only related to differences in blood flow as the relative signal intensity in blood was lower than in lung or skin.

The high amount of lipoproteins in the formed protein corona might have led to a stronger recognition of those particles by scavenger receptors on the surface of macrophages. These receptors show high affinity to lipoproteins and to other ligands showing an anionic charge distribution $[27,28]$. As the largest population of macrophages are located in the liver (Kupffer cells) and the alveolar spaces of the lung (alveolar macrophages) [29], the accumulation of PS-LUT and PSLUT-NH $\mathrm{N}_{2}$ in these organs might be explained by a scavenger receptor mediated interaction with the macrophages of these organs triggered by the lipoproteins in the protein corona [30]. Notably, PS-LUT particle showed only a slight uptake in monocytes and almost no uptake in granulocytes, T lymphocytes as well as B lymphocytes.

The slightly cationic charged particle PS-LUT-NH $(\xi=4 \mathrm{mV})$ shows no aggregation in undiluted as well as in diluted human serum. The LC-MS analysis reveals a high amount of lipoproteins in the formed protein corona, just as for PS-LUT. Our results concerning the formation of the protein corona are in agreement with other findings since it is known that polystyrene particles that have been aminemodified showed a preferential binding of lipoproteins in contrast to carboxy-modified and plain particles [31]. Lipoproteins are involved in the transport of lipids and cholesterol in the bloodstream and might therefore have a clear effect on intracellular transport of particles in vitro and in vivo [32]. This stands in well agreement with the relatively higher lung uptake of this particle compared to PS-COOH and PS-SDS. This increased uptake by the lungs might result from interactions of the protein corona forming lipoproteins with the scavenger receptors of the macrophages.

Furthermore, this particle type shows the most promising in vivo distribution; in addition to the liver, particles of sample PS-LUT-NH could be found in lymphatic as well as non-lymphatic organs. This 
obtained in vivo distribution is in line with the stability in human serum against the formation of high molecular weight aggregates. DLS analysis showed that only PS-LUT- $\mathrm{NH}_{2}$ particles have a radius of $<$ $100 \mathrm{~nm}$ in undiluted serum solution, which makes a longer and more efficient body distribution more likely [33]. Moreover, studies in whole blood showed a high uptake of this particle in monocytes as well as in granulocytes, whereas all other particles are only taken up in significant amounts in monocytes. In addition, PS-LUT-NH 2 particles showed a higher uptake in B lymphocytes compared to all other particles. As explained above, aggregation of NPs might hamper the uptake via endocytosis. Only the PS-LUT-NH $\mathrm{N}_{2}$ particles show a size $<100 \mathrm{~nm}$ $\left(\mathrm{R}_{\mathrm{h}, \mathrm{PS} \text {-LUT-NH2 }}=89 \mathrm{~nm}\right)$ after incubation in blood serum and with that can be taken up via endocytosis in granulocytes. The DLS results are in good agreement with the uptake study as well as the in vivo distribution profile, as the non-aggregating particle is the only one taken up by granulocytes and showed the most promising body distribution of all particles.

Particles of sample PS-LUT-COOH induced no aggregate formation in diluted human serum $\left(c_{\mathrm{S}, \mathrm{iv}}=6 \mathrm{mg} \cdot \mathrm{mL}^{-1}\right)$ while the particles aggregated to structures with a hydrodynamic radius of $R_{\mathrm{h}, \mathrm{Agg} \text {, PS-LUT-COOH }}$ $=250 \mathrm{~nm}$ in undiluted serum $\left(\mathrm{c}_{\mathrm{S} \text {, conc }}=60 \mathrm{mg} \cdot \mathrm{mL}^{-1}\right)$. The investigation of the protein corona revealed a higher enrichment of coagulation factors compared to the other particles. However, apolipoproteins were less frequently detected than on non-functionalized particles and in regard to the acute phase proteins, previous results could be confirmed in the way that a higher number was detected within the protein corona on these compared to other particles. As we have shown before $[18,34]$ and confirmed by this particle set here, in vitro uptake analysis reveals an enhanced uptake of PS-LUT-COOH particles by monocytes in contrast to granulocytes, $\mathrm{T}$ and $\mathrm{B}$ lymphocytes. This particle almost completely allocated to the liver in vivo and almost completely spared other organs. As discussed above, this effect might be caused by the liver- and lungmacrophages recognizing PS-LUT-COOH particles $[27,28]$.

In comparison to the non-functional particles PS-LUT, the protein corona of the carboxy-functionalized particles PS-LUT-COOH illustrated a depletion of lipoproteins which made the interaction with the scavenger receptors of the macrophages less preferable. Accordingly, the diffusion time of the PS-LUT-COOH particles through the lung capillaries might be enhanced, leading to a decreased lung uptake in comparison to PS-LUT particles. In contrast to the other three particle sample, PS-LUT-COOH particles showed almost no signal in the skin. In vitro uptake analysis indicated an enhanced uptake by monocytes in contrast to granulocytes, $\mathrm{T}$ and $\mathrm{B}$ lymphocytes.

The formally negatively charged particle PS-SDS $(\xi=-37 \mathrm{mV})$ induced the strongest aggregation in human serum resulting in aggregates of a size range between $2 \mu \mathrm{m}$ in diluted serum and up to macroscopic precipitation in undiluted human serum. This aggregation might be caused by inter-particle bridging. The strong in vivo uptake by the liver might have resulted from a fast and size dependent recognition by the liver macrophages (Kupffer cells), which have an even higher phagocytotic activity compared to lung macrophages [29]. As Kupffer cells favor the uptake of particles with a diameter between 1-3 $\mu \mathrm{m}$, the uptake of PS-SDS particles, or rather its higher molecular aggregates in the liver, might explain our findings [35,36]. Moreover, the preferential binding of immunoglobulins to this particle sample next to complement and coagulation factors might have led to phagocytosis and the removal from the systemic circulation by cells of the reticuloendothelial system (RES).

The strong aggregation observed with DLS is also consistent with the protein corona studies that showed that this particle sample has the highest amount of adsorbed proteins on the particle surface. The total amount of proteins adsorbed to PS-SDS particles is almost 4 times higher $\left(4.1 \mathrm{mg} \cdot \mathrm{m}^{-2} \mathrm{NP}\right)$ than for the other three NPs $\left(1.0-1.2 \mathrm{mg} \cdot \mathrm{m}^{-2}\right.$ NP). Furthermore, the sample PS-SDS showed additional enrichment of several serum proteins belonging to the group of coagulation and complement factors, which are absent on the three other NPs. These proteins are potential candidates to participate in the cross-linking of PS-SDS particles. Moreover, recognition of the adsorbed complement factors and immunoglobulins results in an enhanced clearance via the different ways of the complement activation cascade leading to opsonization and presentation to macrophages $[31,37]$. Correlating the in vitro data with the aggregation study in DLS leads to the hypothesis, that for the neutrophil granulocytes the size cutoff might be lower compared to monocytes. This hypothesis could explain why PS-SDS particles, as well as the other aggregating particles are only taken up in monocytes in a significant amount in contrast to the non-aggregating particles like PS-LUT-NH2.

\section{Conclusions}

It is well known that surface functionalization of nanocarriers influence their cellular uptake in vitro and organ distribution in vivo. Here we show for the first time, to what extend serum protein binding influences these effects. Our data strongly suggest that aggregate formation mediated by bound serum-proteins as well as the composition of the protein corona itself cause these differences by changing polydispersity/size distribution. The current analysis demonstrates the potential of a combination of dynamic light scattering and protein corona studies as well as in vitro evaluation for predicting in vivo behavior. A precise pre-in vivo-screening gives a better understanding of the final in vivo behavior of NPs.

\section{Acknowledgement}

We are grateful to Dr. Roland Conradi, Department of Transfusion Medicine, University Medical Center Mainz, for providing human blood serum samples and buffy coats. The authors also thank Christine Rosenauer and Diana Wolff for technical assistance, as well as Dr. Karl Fisher for fruitful discussions. We would like to thank the DFG SFB 1066 as funding agency for funding the projects Q1 and Q2.

\section{References}

1. Akhter S, Ahmad I, Ahmad MZ, Ramazani F, Singh A, et al. (2013) Nanomedicines as cancer therapeutics: current status. Curr Cancer Drug Targets 13: 362-378.

2. Zhu ZJ, Posati T, Moyano DF, Tang R, Yan B, et al. (2012) The interplay of monolayer structure and serum protein interactions on the cellular uptake of gold nanoparticles. Small 8: 2659-2663.

3. Walkey CD, Olsen JB, Guo H, Emili A, Chan WC (2012) Nanoparticle size and surface chemistry determine serum protein adsorption and macrophage uptake. J Am Chem Soc 134: 2139-2147.

4. Eberbeck D, Bergemann C, Wiekhorst F, Steinhoff U, Trahms L (2008) Quantification of specific bindings of biomolecules by magnetorelaxometry. J Nanobiotechnology 6: 4 .

5. Tsai DH, Morris MD, DelRio FW, Guha S, Zachariah MR, et al. (2011) Quantitative determination of competitive molecular adsorption on gold nanoparticles using attenuated total reflectance-Fourier transform infrared spectroscopy. Langmuir 27(15): 9302-9313.

6. Walczyk D, Bombelli FB, Monopoli MP, Lynch L, Dawson KA (2010) What the cell "sees" in bionanoscience. J Am Chem Soc 132: 5761-5768.

7. Aggarwal P, Hall JB, McLeland CB, Dobrovolskaia MA, McNeil SE (2009) Nanoparticle interaction with plasma proteins as it relates to particle biodistribution, biocompatibility and therapeutic efficacy. Adv Drug Deliv Rev 61: 428-437. 
Citation: Mohr K, Sommer M, Baier G, Schöttler S, Okwieka P, et al. (2014) Aggregation Behavior of Polystyrene-Nanoparticles in Human Blood Serum and its Impact on the in vivo Distribution in Mice. J Nanomed Nanotechnol 5: 193. doi:10.4172/2157-7439.1000193

8. Markovsky E, Baabur-Cohen H, Eldar-Boock A, Omer L, Tiram G, et al. (2012)Administration, distribution, metabolism and elimination of polymer therapeutics. J Control Release 161: 446-460.

9. Landfester K, Musyanovych A, Mailander V (2010) From Polymeric Particles to Multifunctional Nanocapsules for Biomedical Applications Using the Miniemulsion Process. Journal of Polymer Science Part a-Polymer Chemistry 48: 493-515.

10. Rausch K, Reuter A, Fischer K, Schmidt M (2010) Evaluation of nanoparticle aggregation in human blood serum. Biomacromolecules 11: 2836-2839.

11. Nikiforow I, Adams J, König AM, Langhoff A, Pohl K, et al. (2010) Selfstratification during film formation from latex blends driven by differences in collective diffusivity. Langmuir 26: 13162-13167.

12. Musyanovych A, Rossmanith R, Tontsch C, Landfester K (2007) Effect of hydrophilic comonomer and surfactant type on the colloidal stability and size distribution of carboxyl- and amino-functionalized polystyrene particles prepared by miniemulsion polymerization. Langmuir 23: 5367-5376.

13. Stepanek P (1993) Static and Dynamic Properties of Multiple Light-Scattering Journal of Chemical Physics 99: 6384-6393.

14. Bantle S, Schmidt M, Burchard W (1982) Simultaneous Static and Dynamic Light-Scattering. Macromolecules 15: 1604-1609.

15. Meyer RG, Britten CM, Siepmann U, Petzold B, Sagban TA, et al. (2005) A phase I vaccination study with tyrosinase in patients with stage II melanoma using recombinant modified vaccinia virus Ankara (MVA-hTyr). Cancer Immunol Immunother 54: 453-467.

16. Tenzer S, Docter D, Rosfa S, Wlodarski A, Kuharev J, et al. (2011) Nanoparticle size is a critical physicochemical determinant of the human blood plasma corona: a comprehensive quantitative proteomic analysis. ACS Nano 5: 71557167.

17. Distler U, Kuharev J, Navarro P, Levin Y, Schild H, et al. (2014) Drift timespecific collision energies enable deep-coverage data-independent acquisition proteomics. Nat Methods 11: 167-170.

18. Baumann D, Hofmann D, Nullmeier S, Panther P, Dietze C, et al. (2013) Complex encounters: nanoparticles in whole blood and their uptake into different types of white blood cells. Nanomedicine (Lond) 8: p. 699-713.

19. Shultz LD, Lyons BL, Burzenski LM, Gott B, Chen X, et al. (2005) Human lymphoid and myeloid cell development in NOD/LtSz-scid IL2R gamma null mice engrafted with mobilized human hemopoietic stem cells. J Immunol 174 $6477-6489$.

20. Böckenhoff K, Fischer WR (2001) Determination of electrokinetic charge with a particle-charge detector, and its relationship to the total charge. Fresenius $J$ Anal Chem 371: 670-674

21. Barenholz Y (2012) Doxil ${ }^{\circledR}$--the first FDA-approved nano-drug: lessons learned. J Control Release 160: 117-134.

22. Rivera Gil P, Hühn D, del Mercato LL, Sasse D, Parak WJ, et al. (2010) Nanopharmacy: Inorganic nanoscale devices as vectors and active compounds. Pharmacol Res 62: 115-125.
23. Joshi MD, Unger WJ, Storm G, van Kooyk Y, Mastrobattista E (2012)Targeting tumor antigens to dendritic cells using particulate carriers. J Control Release 161: $25-37$.

24. Gaitanis A, Staal S (2010) Liposomal doxorubicin and nab-paclitaxel: nanoparticle cancer chemotherapy in current clinical use. Methods Mol Biol 624: 385-392.

25. Conner SD, Schmid SL (2003) Regulated portals of entry into the cell. Nature 422: 37-44.

26. Adjei IM, Peetla C, Labhasetwar V (2013) Heterogeneity in nanoparticles influences biodistribution and targeting. Nanomedicine (Lond) 422: 37-44.

27. Kodama T, Doi T, Suzuki H, Takahashi K, Wada Y, et al. (1996) Collagenous macrophage scavenger receptors. Curr Opin Lipidol 7: 287-291.

28. Krieger M, Herz J (1994) Structures and functions of multiligand lipoprotein receptors: macrophage scavenger receptors and LDL receptor-related protein (LRP). Annu Rev Biochem 63: 601-637.

29. Laskin DL, Weinberger B, Laskin JD (2001) Functional heterogeneity in liver and lung macrophages. J Leukoc Biol 70: 163-170.

30. Neyen C, Plüddemann A, Mukhopadhyay S, Maniati E, Bossard M, et al. (2013) Macrophage scavenger receptor a promotes tumor progression in murine models of ovarian and pancreatic cancer. J Immunol 190: 3798-805.

31. Lundqvist M, Stigler J, Elia G, Lynch I, Cedervall T, et al. (2008) Nanoparticle size and surface properties determine the protein corona with possible implications for biological impacts. Proc Natl Acad Sci U S A 105: 14265-14270.

32. Anderson NL, Anderson NL (2012) The human plasma proteome: history character, and diagnostic prospects. Mol Cell Proteomics 1: 845-867.

33. Hirsjärvi S, Dufort S, Gravier J, Texier I, Yan Q, et al. (2013) Influence of size surface coating and fine chemical composition on the in vitro reactivity and in vivo biodistribution of lipid nanocapsules versus lipid nanoemulsions in cancer models. Nanomedicine 9: 375-387.

34. Hofmann D, Mailander V (2013) Pharmacology of nanocarriers on the microscale: importance of uptake mechanisms and intracellular trafficking for efficient drug delivery. Nanomedicine (Lond) 8: 321-323.

35. Doshi N, Mitragotri S (2010) Macrophages recognize size and shape of thei targets. PLoS One 5: e10051.

36. Champion JA, Walker A, Mitragotri S (2008) Role of particle size in phagocytosis of polymeric microspheres. Pharm Res 25: 1815-1821.

37. Bertrand N, Leroux JC (2012) The journey of a drug-carrier in the body: an anatomo-physiological perspective. J Control Release 161: 152-163. 